\title{
Improving Student Asking Activity by Using Learning Start with a Question (LSQ) Learning Method
}

\author{
Patimah Delasari, Fajar Nugraha, Riza Fatimah Zahrah \\ Universitas Perjuangan Tasikmalaya \\ patimahdelasari310@gmail.com
}

\section{Article History}

accepted 05/11/2020

approved 10/11/2020

published 01/02/2021

\begin{abstract}
This study aims to meet whether the Learning Start With A Question (LSQ) learning method can be used to improve the results of questioning activeness in grade IV SD Negeri Pereng. This research method is Classroom Action Research (PTK), using the model of Kesmis and Mc. Taggart. The subjects in this study were the fourth grade students of SD Negeri Pereng, Tasikmalaya Regency, totaling 17 students. Data collection techniques in the form of student observation sheets, tests to determine the ability to ask questions and administrative learning documents. The results showed that the use of the Learning Start With A Question (LSQ) learning method in social studies learning could increase the activeness of the fourth grade students of SD Negeri Pereng, Tasikmalaya Regency. Based on the test results obtained by students at the end of each cycle, it showed an increase in student questioning activity. The average completeness in the first cycle was 47.35, and the average completeness in the second cycle was 67.64, while the average of the third cycle was 78.82. The results show that the quality of the learning process, especially in questioning activeness, has increased.
\end{abstract}

Keywords: activeness asked, LSQ

\begin{abstract}
Abstrak
Penelitian ini bertujuan untuk memenuhi apakah metode pembelajaran Learning Start With A Question (LSQ) dapat digunakan untuk meningkatkan hasil keaktifan bertanya pada siswa kelas IV SD Negeri Pereng. Metode penelitian ini adalah Penelitian Tindakan Kelas (PTK), menggunakan model Kesmis dan Mc. Taggart. Subjek dalam penelitian ini adalah siswa kelas IV SD Negeri Pereng Kabupaten Tasikmalaya yang berjumlah 17 siswa. Teknik pengumpulan data berupa lembar observasi siswa, tes untuk mengetahui kemampuan bertanya dan dokumen administrative pembelajaran. Hasil penelitian menunjukan bahwa penggunaan metode pembelajaran Learning Start with A Question (LSQ) pada pembelajaran IPS dapat meningkatkan keaktifan betanya siswa kelas IV SD Negeri Pereng Kabupaten Tasikmalaya. Berdasarkan hasil tes yang diperoleh siswa pada setiap akhir siklus menunjukan peningkatan keaktifan bertanya siswa. Rata-rata ketuntasan Siklus I yaitu 47,35 , dan rata-rata ketuntasan pada siklus ke II yaitu 67,64 sedangkan siklus ke III rata-rata sebesar 78,82 . Hasil menunjukan bahwa kualitas proses pembelajaran terutama dalam keaktifan bertanya menjadi meningkat.
\end{abstract}

Kata kunci: keaktifan bertanya, $L S Q$

Social, Humanities, and Education Studies (SHEs): Conference Series https://jurnal.uns.ac.id/shes

p-ISSN 2620-9284

e-ISSN 2620-9292 


\section{PENDAHULUAN}

Sudah menjadi tugas pendidik dalam keterampilan dasar bertanya pada saat proses pembelajaran supaya tidak pasif pada saat proses belajar berlangsung. Sesuai dengan keadaan sekarang yaitu kurikulum 2013 bahwa siswa harus lebih aktif tidak hanya menerima materi dari guru saja. Sesuai dengan UU No. 20 Tahun 2003 Pendidikan adalah usaha sadar dan terencana untuk mewujudkan suasana belajar dan proses pembelajaran agar peserta didik secara aktif mengembangkan potensi dirinya untuk memiliki kekuatan spiritual keagamaan, pengendalian diri, kepribadian, kecerdasan, akhlak mulia, serta keterampilan yang diperlukan dirinya, masyarakat, bangsa dan Negara.

Berdasarkan hasil pra tindakan yang telah dilakukan menunjukan bahwa keaktifan bertanya siswa pada mata pelajaran IImu Pengetahuan Sosial di SDN Pereng kelas IV, yang berjumlah 17 siswa yang masih terlihat sangat rendah. Dikelas IV $88,23 \%$ (15 siswa) yang mengalami kurang aktif dalam bertanya saat proses pembelajaran pada mata pelajaran IPS dalam materi keberagaman sosial dan budaya, dan hasil dalam keaktifan bertanya siswa hanya $11,76 \%$ yaitu 2 siswa yang mencapai ketuntasan keaktifan bertanya siswa. Rata-rata nilai dikelas yaitu 44,11.

Ternyata selama ini proses pembelajaran hanya menggunakan metode konvesional. Guru tidak menggunakan alat untuk membatu siswa dalam memahami materi yang diajarkan oleh guru. Dalam hal ini guru masih belum berhasil untuk menjadikan siswa aktif dalam belajar khusunya dalam bertanya karena pada proses pembelajaran terlalu berpusat pada guru. Menurut Rifa'i (2012 : 206) dalam Erma (2016 : 16) Kegiatan bertanya merupakan bagian penting dalam pembelajaran yaitu menggali informasi, menginformasikan apa yang sudah di ketahui dan mengarahkan perhatian pada aspek yang belum diketahui.

Berdasarkan masalah-masalah tersebut, maka dari itu peneliti memberikan solusi penyelesaiannya dengan menerapakan metode pembelajaran yang tepat, sesuai materi dan pokok bahasan yang akan diajarkan. Agar siswa tidak terus berada pada rasa bosan saat pembelajaran, sebagai jalan keluarnya atau solusi dari permasalahan di atas observer akan mencoba menerapkan Metode Pembelajaran Learning Start Whit A Question ( $L S Q$ ) dalam mata pelajaran IPS dalam materi keberagaman sosial dan budaya. Dimana proses belajar siswa akan lebih aktif dalam bertanya supaya tidak menimbulkan kejenuhan dan semakin semangat, dan ada perubahan dalam pembelajaran kearah yang lebih baik.

Berdasarkan uraian permasalahan yang sudah di paparkan, peneliti mengambil sebuah judul yang berkaitan dengan permasalahan tersebut yaitu : Meningkatkan Keaktifan Bertanya Siswa dengan Menggunakan Metode Pembelajaran Learning Start With A Question ( $L S Q$ ) pada Materi keberagaman sosial dan budaya. Penelitian ini dilaksanakan untuk mencapai beberapa tujuan, diantaranya; 1) Mendeskripsikan rencana pembelajaran dengan menggunakan metode pembelajaran Learning Start With A Question (LSQ) dalam meningkatkat keaktifan bertanya siswa. 2) Mendeskripsikan pelaksanaan pembelajaran dengan menggunakan metode pembelajaran Learning Start With A Question (LSQ) dalam meningkatkat keaktifan bertanya siswa. 3) Mendeskripsikan peningkatan keaktifan bertanya siswa dengan menggunakan metode pembelajaran Learning Start With A Question (LSQ). 


\section{METODE}

Metode penelitian yang digunakan dalam penelitian ini adalah metode Penelitian Tindakan Kelas (PTK) dengan model Kemmis-Tagart yang merupakan suatu tindakan reflektif guru untuk memperbaiki belajar mengajar. Menurut Rochiatin dalam Asip (2006 : 71) Penelitian Tindakan Kelas adalah bagaimana sekelompok guru dapat mengorganisasikan kondisi praktik pembelajaran mereka, dan belajar dari pengalaman sendiri. Desain PTK yang digunakan adalah Desain PTK menurut Mc. Taggart dan Stephen kemiss dalam Asip (2018 : 79) Model ini dikembangkan 1988. Penelitian tindakan dapat dilakukan dengan beberapa siklus. Jumlah siklus tergantung pada kriteria keberhasilan dan kepuasan peneliti. Setiap siklus terdiri dari 4 kegiatan utama, yaitu perencanaan (plan), tindakan (act), pengamatan (observer) dan refleksi.

Adapun teknik pengumpulan data dalam penelitian ini yaitu observasi, tes, dan dokumentasi. Menurut Arikunto (2010: 203) instrumen penelitian adalah alat atau fasilitas yang digunakan oleh peneliti dalam mengumpulkan data agar pekerjaannya lebih mudah dan hasilnya lebih baik, dalam arti cermat, lengkap dan sistematis sehingga lebih mudah diolah. instrumen dalam pengumpulan data yang akan dipergunakan dalam penelitian ini berupa lembar panduan observasi, berupa APKG I, APKG II, lembar tes, teknik dokumentasi berupa adanya RPP, kisi-kisi tes, dan materi ajar.

\section{HASIL DAN PEMBAHASAN}

Hasil penelitian ini mengacu pada rumusan masalah yang tertuang dalam BAB I meliputi: Bagaimana perencanaan metode pembelajaran Learning Start With $A$ Question (LSQ) untuk siswa SD kelas IV dalam mata pelajaran IPS pada materi keberagaman sosial dan budaya?, Bagaimana pelaksanaan metode pembelajaran Learning Start With A Question (LSQ) untuk siswa SD kelas IV dalam mata pelajaran IPS pada materi keberagaman social dan budaya?, Adakah peningkatan keaktifan bertanya siswa kelas IV dalam mata pelajaran IPS pada materi keberagaman social dan budaya setelah menerapkan metode pembelajaran Learning Start With A Question (LSQ) ?. Adapun penjelasan masing-masing data pada setiap rumusan masalah adalah sebagai berikut:

Berdasarkan hasil pengamatan tentang keaktifan bertanya siswa, sesuai dengan rumusan masalah, dengan deskripsi sebagai berikut :

\section{Bagaimana Perencanaan Pembelajaran dengan menggunakan metode Learning Start With A Question (LSQ)?}

Perencanaan pembelajaran pada siklus I, masih ada kekurangan mulai dari mempersiapkan cara menerapkan metode LSQ. Karena mungkin ini untuk pertama kalinya dilakukan di kelas IV maka dari itu masih kaku. Untuk penilaian dari perencanaan pembelajaran atau APKG I yaitu rata-rata 89,28. Untuk perencanaan pembelajaran di siklus II ada peningkatan dari siklus pertama, karena ada masukan dari ibu guru wali kelas IV setelah siklus I dilakukan. Untuk nilai rata-rata APKG I pada siklus ke dua yaitu 92,85. Selanjutnya perencanaan pembelajaran di siklus ke III ada peningkatan lagi dari siklus I dan II yaitu untuk rata-ratanya 97,32. Dari hasil yang terdapat pada setiap siklus menunjukan peningkatan dalam menyusun rencana pembelajaran kelas IV di SD Negeri Pereng dalam pembelajaran IPS. Jadi perencanaan pembelajaran harus ini sangat berpengaruh pada kegiatan pembelajaran supaya terarah tujuannya. Terbukti sesuai dengan teori tentang Perencanaan pembelajaran (Ghazali et.all, 2019; Uno, 2014 :2) yaitu Inti dari perencanaan pembelajaran adalah kegaiatan pemilihan, penetapan, dan pengembangan metode bersadarkan pada kondisi pengaran yang ada. Perencanaan pembelajaran menjawab 
pertanyaan apa yang akan dilakukan selama proses pembelajaran. Sedangkan menurut Vivi \& Sofia (2019:51) perencanaan tidak menjadi sesuatu yang harus dilakukan tetapi menjadi garis besar yang bisa dilakukan untuk mencapai tujuan pembelajaran.

\section{Bagaimana Pelaksanaan Pembelajaran dengan menggunakan metode Learning Start With A Question (LSQ)?}

Pelaksanaan pembelajaran di siklus I kalau di lihat di rata-rata penilaian yaitu 87,06 sudah mencapai ketentuan, tetapi dalam hasil yang diterima oleh siswa masih sangat rendah. Karena belum pernah menerapkan metode pembelajaran $L S Q$. Untuk siklus II pelaksanaan pembelajaran sudah cukup baik dilakukan oleh guru, dan sudah ada peningkatan dari siklus I yaitu nilai rata-ratanya 92,24 dan ada peningkatan pada siswa. Pada siklus ke III untuk pelaksanaan pembelajaran sudah mencapai yang ditentukan yaitu 96,55 dan hasil peningkatan pada siswa nya pun sangat baik sekali, karena memperbaiki kekurangan dari siklus I dan II. Dari hasil yang terdapat pada setiap siklus menunjukan peningkatan dalam proses pelaksanaan pembelajaran kelas IV di SD Negeri Pereng dalam pembelajaran IPS. Karena pelaksanaan pembelajaran merupakan penerapan dari rencana pembelajaran yang sudah di susun seblum terjun pada kegiatan pembelajaran langsung kepada siswa yang dilakukan oleh guru atau pengajar maka dari itu terbukti sesuai dengan teori tentang pelaksanaan pembelajaran (Dewi \& Primayana, 2019; Uno \& Lamatenggo, 2018 : 187) yaitu guru merupakan desainer atau perancang pembelajaran sekaligus pengelola atau pelaksanaan pembelajaran. Sebagai pelaksana pembelajaran dapat dilihat dari keberhasilannya dari performance guru ketika mengajar.

\section{Bagaimana Peningkatan keaktifan bertanya dengan menggunakan metode Learning Start With A Question (LSQ)?}

Untuk peningkatan keaktifan bertanya pada siklus I sangat rendah sekali, karena belum paham apa yang harus dilakukan, belum terbiasa untuk mengajukan pertanyaan, dan rasa malu yang sangat besar sekali, sehingga pada siklus ini hanya ada dua siswa yang mampu mengajukan pertanyaan. Dengan rata-rata 47,35. Maka dari itu dilakukan lagi penelitian pada siklus ke II karena siklus pertama masih belum selesai. Pada siklus ke satu siswa sangat kurang pada aspek bertanya secara lisan contohnya pada berani bertanya dan percaya diri dalam mengajukan pertanya sangat kurang sekali. Dalam aspek tulisan sudah cukup bisa tapi cara bahasanya yang maih kurang.

Pada siklus II untuk peningkatan keaktifan bertanya siswa ada perubahan cukup baik dari pada siklus pertama yaitu menjadi 7 orang siswa yang mampu mencapai indikator yang ditentukan. Dengan alasan siswa sudah mulai paham harus apa yang dilakukan, paham yang di jelaskan meski hanya bertambah 5 siswa yang mampu meningkatkan keaktifan bertanya, persentase di siklus II untuk peningkatan keaktifan bertanya masih kurang dengan apa yang di targetkan, yaitu dengan rata-rata 67,64 maka dari itu peneliti harus tetap melakukan penelitian sampai mencapai pada yang sudah di tentukan yaitu dengan cara melanjutkan pada siklus ke III. Untuk peningkatan keaktifan bertanya siswa, dan pada siklus ke III untuk peningkatan keaktifan bertanya sudah menacapai pada kriteria yang sudah ditentukan yaitu dengan rata-rata 78,82 , karena pada siklus III siswa sudah paham dan rasa percaya diri yang baik dan mulai terbiasa untuk melawan rasa malu meningkatkan rasa percaya diri dengan baik.

Maka dari ketiga rumusan masalah yang sudah di jabarakan dengan smenerapkan metode pembelajaran Learning Star With A Question (LSQ) merupakan salah satu metode yang mengajak siswa untuk aktif bertanya dalam kegiatan belajar mengajar dan menumbuhkan rasa percaya diri siswa, yang terbukti adanya peningkatan hasil keaktifan bertanya siswa dan peningkatan aktivitas guru dalam 
mengajar dari siklus I, II dan siklus III yanag dapat dilihat pada diagram sebagai berikut:

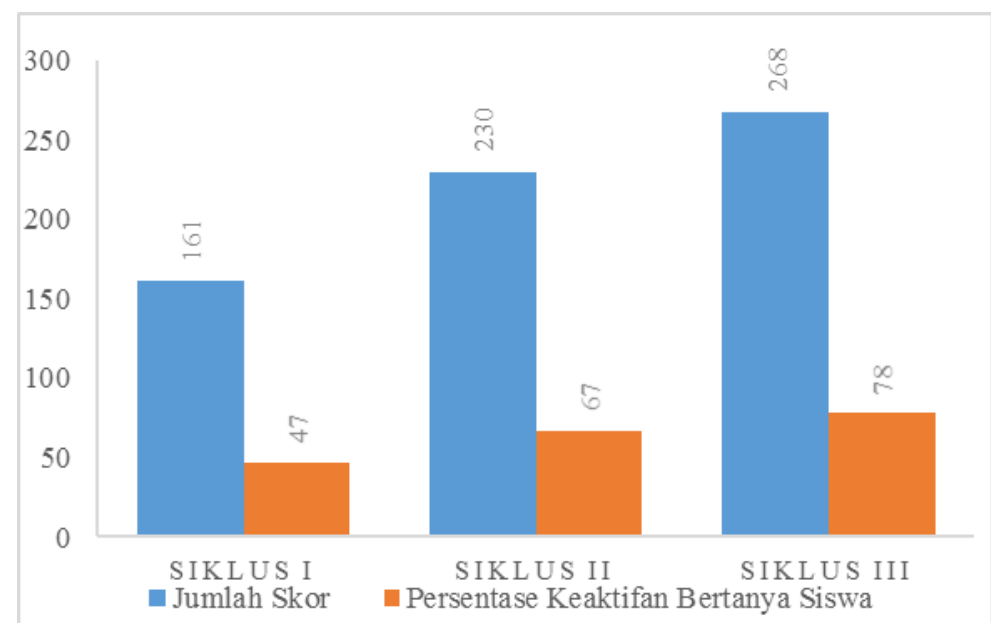

Gambar 1. Diagram Rata-rata peningkatan keaktifan bertanya siswa Setiap Siklus SDN Pereng

Berdasarkan diagram 1 peningkatan hasil keaktifan bertanya siswa kelas IV SD Negeri Pereng menunjukan siklus I jumlah skor yang di peroleh yaitu 161 dengan ratarata keaktifan bertanya siswa yaitu $(47,35)$, sangat rendah di bandingkan dengan siklus II yaitu jumlah skor 230 dengan rata-rata keaktifan bertanya yaitu $(67,64)$ tetapi belum sampai pada kriteria idealnya, kriteria yang berhasil yaitu pada siklus III dengan jumlah skor 268 dengan rata-rata keaktifan bertanya yaitu $(78,82)$. Maka dapat disimpulkan bahwa keaktifan bertanya siswa kelas IV SDN Pereng mengalami peningkatan yang signifikan sehingga telah mencapai nilai ketuntasan bertanya siswa yang telah ditentukan yaitu $70 \%$.

\section{SIMPULAN}

Berdasarkan hasil dan pembahasan dari penelitian yang telah dilakukan di kelas IV SD Negeri Pereng dapat disimpulkan sebagai berikut:

1. Perencanaan penggunaan metode pembelajaran Learning Start With $A$ Question (LSQ) untuk meningkatkan keaktifan bertanya siswa berjalan dengan baik. Perencanaan dilakukan dengan membuat RPP, media pembelajaran, dan materi pelajaran yang disesuaikan dengan langkah-langkah pada metode pembelajaran Learning Start With A Question (LSQ). Terbukti dengan adanya peningkatan perencanaan pembelajaran pada Siklus I mendapatkan skor 100 dengan rata-rata 89,28. Kemudian siklus II mendapatkan skor 104 dengan ratarata 92,85 dan siklus III mendapatkan skor 109 dengan rata-rata 97,32.

2. Pelaksanaan penggunaan metode pembelajaran Learning Start With $A$ Question (LSQ) untuk meningkatkan keaktifan bertanya siswa sebagian besar telah sesuai dengan perencanaan pembelajaran, walaupun terdapat beberapa kenadala dari siklus I, II dan tiga seperti siwa belum memahami langkahlangkah metode pembelajaran Learning Start With A Question (LSQ). Terbukti dengan adanya peningkatan plaksanaan pembelajaran pada Siklus I mendapatkan skor 101 dengan rata-rata 87,06. Kemudian siklus II mendapatkan skor 107 dengan rata-rata 92,24 dan siklus III mendapatkan skor 112 dengan rata-rata 96,55.

3. Pembelajaran yang dilakukan pada mata pelajaran IPS yang terletak pada bagian tema 1 subtema 1 tentang keberagaman social dan budaya, dengan tiga siklus dapat meningkatkan keaktifan bertanya siswa. Terbukti dengan 
adanya peningkatan keaktifan bertanya siswa pada siklus I dengan rata-rata 47,35, siklus II dengan rata-rata 67,64 dan nilai rata-rata siklus III yaitu 78,82.

\section{DAFTAR PUSTAKA}

Dewi, P \& Primayana. (2019). Effect of learning module with setting contextual teaching and learning to increase the understanding of concepts. Internasional Journal of Education and Learning. 1(1(2019)), 19-26. Doi: https://doi.org/10.31763/ijele.vlil.26

https://kelembagaan.ristekdikti.go.id UU No 20 Tahun 2003

Sufiati, Vivi \& Sofia. (2019). Peran perencanaan Pembelajaran untuk performance mengajar guru pendidikan anak usia dini. Madiun : Universitas PGRI Madiun.

Suryadi, Asip \& Ika. (2018). Menggagas Penelitian Tindakan Kelas Bagi Guru. Bandung : PT Remaja Rosdakarya.

Uno,H.B. (2014). Perencanaan Pembelajaran. Bandung: Bumi Aksara

Yafi, Erma. (2016) . Hubungan Keaktifan Bertanya Siswa dengan Hasil Belajar.Universitas Negeri Semarang.

Zaini \& dkk. (2008). Strategi Pembelajaran Aktif. Yogyakarta :Pustaka Insan Madani. 